\title{
$\mathrm{LC} / \mathrm{MS} / \mathrm{MS}$ 를 이용한 대기 중 PFOA 및 PFOS의 오염 수준 조사
}

\author{
김경수 ${ }^{1, \star} \cdot$ 신박민 $^{2} \cdot$ 연진모 $^{3} \cdot$ 가재정 $^{4} \cdot$ 김용준 $^{4} \cdot$ 조천래 $^{5}$ \\ 1전북대학교 환경공학과, ${ }^{2}$ 한국기초과학지원연구원 질량분석연구부, \\ 3국립환경과학원 화학물질거동연구과, ${ }^{4}$ 청주대학교 환경공학과, \\ 5 국립환경과학원 위해성평가과 \\ (2009. 9. 28. 접수; 2009. 12. 25. 승인)
}

\section{Investigation of pollution level for PFOA and PFOS in ambient air using LC/MS/MS}

\author{
Kyoung-Soo Kim ${ }^{1, \star}$, Park-Min Shin ${ }^{2}$, Jin-Mo Yeon ${ }^{3}$, Jae-Jong $\mathrm{Ka}^{4}$, \\ Yong-Jun $\mathrm{Kim}^{4}$ and Chon-Rae Cho ${ }^{5}$ \\ ${ }^{1}$ Department of Environmental Engineering, Chonbuk National University, Jeonju, 561-756, Korea \\ ${ }^{2}$ Division of Mass Spectrometry, Korea Basic Science Institute, Cheongwon, 363-833, Korea \\ ${ }^{3}$ Chemical Behavior Research Division, National Institute of Environmental Research, Incheon, 404-708, Korea \\ ${ }^{4}$ Department of Environmental Engineering, Cheongju University, Cheongju, 360-764, Korea \\ ${ }^{5}$ Risk Assessment Division, National Institute of Environmental Research, Incheon, 404-708, Korea
}

(Received September 28, 2009; Accepted December 25, 2009)

\begin{abstract}
요 약: 본 연구에서 청주지역 대기 중 PFOA 및 $\mathrm{PFOS}$ 의 오염수준을 조사하기 위해 공단, 주거/상업 및 농 촌지역에서 각각 가스상 및 입자상 시료를 채취하였다. 또한 계절적 변화를 조사하기 위해 겨울철, 봄철 및 여름철에 각각 채취하였다. 대기 중 PFOA 및 PFOS의 농도는 각각 불검출 $8.02 \mathrm{pg} / \mathrm{m}^{3}$ (평균 $2.33 \mathrm{pg} / \mathrm{m}^{3}$ )과 $1.68-6.94 \mathrm{pg} / \mathrm{m}^{3}$ (평균 $3.12 \mathrm{pg} / \mathrm{m}^{3}$ )으로 검출되었다. 이들 농도는 외국과 유사하거나 낮은 수준을 보였다.

Abstract: To investigate pollution level of PFOA and PFOS in ambient air, Cheongju city, gaseous and particulate samples were collected at industrial, residential/commercial, and rural region, respectively. Samples were collected in winter, spring, and summer season in order to examine seasonal variation of PFOA and PFOS. The concentration range of PFOA and PFOS was presented as N.D. $\sim 8.02 \mathrm{pg} / \mathrm{m}^{3}$ with an average of $2.33 \mathrm{pg} / \mathrm{m}^{3}, 1.68 \sim 6.94 \mathrm{pg} / \mathrm{m}^{3}$ with an average of $3.12 \mathrm{pg} / \mathrm{m}^{3}$. These levels were lower than or similar to those of other countries.
\end{abstract}

Key words: PFOA, PFOS, LC-MS/MS, ambient air

1. 서

산업의 발전과 생활환경 개선의 이면에는 환경 및
생태계에 대한 악영향의 문제들이 있어 왔으며, 잘 알 려진 물질로서 냉매로 이용되는 프레온가스, 농약의 $\mathrm{DDT}$, 절연유 중 PCBs 및 새집증후군에 관여하고 있

Corresponding author

Phone : +82-(0)63-270-2448 Fax : +82-(0)63-270-2449

E-mail : skysil99@empal.com 


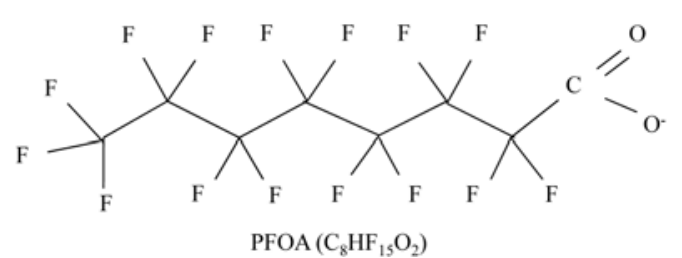

Fig. 1. Chemical structures of PFOA and PFOS.

는 포름알데히드 등이 있다. 사용 당시에는 그 획기적 인 특성에 가려 알려지지 않았던 악영향이 시간이 지 남에 따라 나타나기 시작하여 문제가 될 시기에는 이 미 막대한 영향을 미치고 있는 경우가 많다. 이 때문 에 최근 $\mathrm{EU}$ 를 비롯한 선진국에서는 “사전예방의 원 칙"을 도입하고 있기도 하다.

과불화화합물은 인공적으로 합성된 유기불소화합물 로 환경중에서 분해되기 어려운 난분해성 물질이며, 이러한 난분해성, 즉 잔류성의 특징은 불소와 골격인 탄소와의 결합인 공유결합에 의한 것이다. 또한 소수 성과 친유성을 갖는 기존의 $\mathrm{POPs}$ 와 달리 소수성과 소 유성을 갖는 과불화화합물은 물, 기름, 먼지 등에 대 한 저항성이 크고, 전기절연성, 발수성, 발유성, 표면 장력 저하 등의 성질을 가지고 있기 때문에 1950년대 부터 공업적으로 불소계 계면활성제를 생산하고 유기 합성분야를 비롯한 카페트, 피혁제품, 종이 등의 방 수·방오제, 정전기방지제, 폴리머중합에 필요한 유화 제, 왁스, 식품기구나 조리기구의 코팅제, 고무, 수지, 의약 - 농약 등 매우 다양한 분야에 다량으로 사용되어 왔다.

이러한 과불화화합물은 1999 년 $3 \mathrm{M}$ 사의 유기불소계 화합물의 제조공정에서 근무하는 종업원의 혈청에서 과불화화합물의 하나인 PFOS (perfluorooctane sulfonate, $\mathrm{C}_{8} \mathrm{~F}_{17} \mathrm{SO}_{3}^{-}$)가 최고 $12.83 \mathrm{ppm}$ 으로 검출되어 최초로 문제화되었다. 이를 계기로 2000 년 5월 $3 \mathrm{M}$ 사는 50년 이상 생산을 계속해온 과불소화제품을 시장으로부터 수거하기로 발표하였다. 이 후 세계적으로 과불화화합 물 관련 연구가 수행되어 대기, 물, 토양, 생물 중에서 과불화화합물이 검출되었으며, 그 주요한 오염은 PFOS와 PFOA (perfluorooctanoic acid, $\mathrm{C}_{7} \mathrm{~F}_{15} \mathrm{COO}^{-}$)라 고 하는 2 가지 물질임이 판명되었다. ${ }^{1-3}$ Fig. 1 에 PFOA 및 PFOS의 분자 구조를 나타내었다.

이들 물질의 용도를 살펴보면, PFOS는 방수, 방유 및 오염방지를 위한 직물, 카펫, 금속 도금, 소방용 발 포제, 코팅 및 코팅 첨가제, 산업용/가정용 세제, 농약, 난연제, 유압유, 계면활성제 등 산업 및 생활 환경에

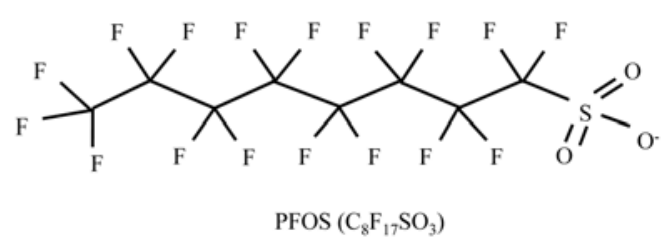

서 다양하게 사용되었으며, $\mathrm{PFOA}$ 의 경우 테플론 불소 수지 생산과정에서 촉매 역할을 하는 특수 계면활성제 로 불소수지를 만드는 업체에서는 반드시 사용할 수 밖에 없는 물질로 테플론 프라이팬, 소화제, 윤활제, 그 리스, 왁스, 도료, 접착제의 첨가제, 전자부품의 표면처 리제, 종이컵 등 1 회용 음식 용기 등에 사용되어 왔다.

현재까지 이루어진 동물실험 결과 이들 물질의 독 성은 주로 간에 영향을 미치고 있으며 체중감소, 경련, 간세포 괴사, 구토, 운동신경 장애, 혈액 이상, 태아 사망, 장기의 형성 이상 등 다양한 장해를 일으 키는 것으로 보고되고 있다. ${ }^{4-6}$ 이들 물질들은 일단 체 내에 들어오게 되면 수년간 체내를 순환하게 되며, 새 로운 노출이 없다고 하더라도 체내의 조직이나 근육 에 축적된 $\mathrm{PFOA}$ 나 $\mathrm{PFOS}$ 의 중량의 절반을 체외로 배 출시키는데 약 4.4 년이 걸릴 것으로 추정하고 있다. ${ }^{7}$ 그러나 인간은 거의 매일 소비자용품이나 환경오염을 통해 노출되고 있기 때문에, 만일 소비자용품에 과불 화화합물의 사용이 금지되어도 인간은 환경오염에 의 한 경로(수돗물, 식품, 공기 등)를 통해서 적지 않은 양의 과불화화합물을 섭취하게 된다. 이러한 독성을 가진 과불화화합물은 거의 모든 환경매체에서, 그리고 특정 오염원이 없는 극지방 및 원거리 지역에서까지 다양하게 검출되고 있으며, ${ }^{8-11} \mathrm{PBT}$ (persistent, bioaccumulative, toxic) 특성 및 장거리이동 가능성 때문에 $\mathrm{OECD}$ 는 PFAs (perfluoroalkylates)를 잠재적 $\mathrm{POPs}$ 로 간 주하였다.

그러나 아직까지 과불화화합물의 물성, 배출원, 배 출량 및 환경 중 이동경로 등에 대한 정보들이 명확 히 밝혀지지 않은 상황이며, 국내에서는 많은 연구가 이루어지지 못했다. 최근 일부 국내연구자에 의해 $\mathrm{PFOA} / \mathrm{PFOS}$ 의 배출원으로 알려진 하수처리장 및 연 계 하천에 대한 연구나 혈액 중 $\mathrm{PFOA/PFOS}$ 에 대한 연구가 수행되어져 왔으나 ${ }^{12,13}$ 인체 노출 경로이며 환 경 중 이동경로 중 하나인 대기에 대한 연구는 보고 되지 않았다.

따라서 본 연구에서는 국내에서는 아직까지 활발한 
Table 1. Information on ambient air sampling

\begin{tabular}{clcccc}
\hline \hline Sampling region & Sampling period & $\begin{array}{c}\text { Mean temperature } \\
(\mathrm{K})\end{array}$ & $\begin{array}{c}\text { TSP Conc. } \\
\left(\mu \mathrm{g} / \mathrm{m}^{3}\right)\end{array}$ & $\begin{array}{c}\text { Mean wind } \\
\text { speed }(\mathrm{m} / \mathrm{s})\end{array}$ & $\begin{array}{c}\text { Relative humidity } \\
(\%)\end{array}$ \\
\hline \multirow{2}{*}{ Industrial } & 16 17 Jan '08 & 267.5 & 168.4 & 1.8 & 45.5 \\
& 16 17 April '08 & 290.8 & 97.2 & 2.1 & 51.0 \\
(E127.26.20, N36.38.30) & 27 28 Aug '08 & 296.8 & 41.7 & 1.45 & 66.8 \\
\hline \multirow{2}{*}{ Residential/Commercial } & 18 19 Jan '08 & 270.1 & 111.4 & 1.1 & 44.5 \\
(E127.29.8, N36.39.42) & 18 19 April '08 & 291.7 & 125.0 & 1.5 & 43.8 \\
& 29 30 Aug '08 & 298.0 & 41.7 & 1.35 & 65.5 \\
\hline Rural & 17 18 Jan '08 & 267.9 & 111.3 & 1.2 & 43.1 \\
(E127.28.55, N36.41.21) & 15 16 April '08 & 289.8 & 152.8 & 1.3 & 45.6 \\
\hline
\end{tabular}

연구가 이루어지고 있지 않은 과불화화합물( $\mathrm{PFOA}$ 및 PFOS)을 대상물질로 대기 중 오염 수준을 조사하였다.

\section{2. 실험방법}

\section{1. 시약 및 기구}

표준물질은 Wellington사의 PFOA, PFOS, MPFOA, $\mathrm{MPFOS}$ 를 이용하였으며, 메탄올, 아세톤 등의 용매는 J.T. Baker사의 HPLC 등급 시약을 사용하였고, ammonium acetate는 특급시약을 사용하였다. 증류수 는 Milli-Q water purification system을 통과한 3차 증 류수를 이용하였다.

실험에 사용된 초자 등의 기구는 사용 전에 아세 톤, 메탄올로 각각 3회씩 세척한 후에 사용하였으며, 과불화화합물이 용출되어져 나오는 것으로 알려진 테플론 재질은 사용하지 않았다. 기기분석을 위한 최종 농축 바이얼 뚜껑의 셉터도 폴리프로필렌 재질 을 사용하였다.

\section{2. 시료 채취}

시료 채취 지점은 청주시의 공단지역, 주거/상업지 역 및 농촌지역을 조사대상 지점으로 선정하였다. 또 한 계절적 차이 및 특성을 조사하기 위해 겨울철, 봄 철, 여름철 3 회에 걸쳐서 시료를 채취하였다. 시료의 채취는 SIBATA사의 고용량공기포집 기(HV-1000F)를 이용하여 $700 \mathrm{~L} / \mathrm{min}$ 의 유속으로 약 24시간 동안 $1,000 \mathrm{~m}^{3}$ 이상 채취하였으며, 채취시 XAD-2 수지를 PUF로 샌드위치한 곳에 가스상 물질을, 석영유리필터 $(\mathrm{QFF})$ 에는 입자상 물질을 각각 나누어 채취하였다. Table 1에 시료채취정보를 정리하여 나타내었다. 가스 상 및 입자상의 채취된 시료의 $1 / 2$ 은 분석용 시료로
사용하였으며, 나머지 $1 / 2$ 은 다른 POPs 물질 분석을 위해 $-25{ }^{\circ} \mathrm{C}$ 이하의 냉동고에 보관하였다.

\section{3. 분석 방법}

\subsection{1. 추출 및 전처리}

$\mathrm{PFOA}$ 및 $\mathrm{PFOS}$ 의 분석에 있어서 추출방법은 ASE, ${ }^{14}$ Soak, ${ }^{15}$ Soxhlet ${ }^{16}$ 및 초음파 ${ }^{17}$ 를 이용한 방법들 이 사용되고 있으며, 정제방법으로는 고상추출(SPE, solid phase extraction)의 cartridge를 이용 14-17하고 있다. 특히 물 시료의 경우 SPE를 이용하여 시료 중 과불화 화합물을 cartridge로 농축 - 흡착 시킨 후 소량의 용매 를 이용하여 용출시키는 방법을 사용하고 있다. 본 연 구에서는 대기 시료의 경우 특별한 전처리가 필요하 지 않다고 판단되어, Kim and Kannan (2007)의 방법 을 참고로 하여 메탄올을 사용하여 6 시간 이상 Soxhlet 추출을 한 후 다검체농축기로 2 3 mL정도까 지 농축한 다음, 질소농축기를 이용하여 완전히 건조 시킨 후 메탄올을 이용하여 $1 \mathrm{~mL}$ 로 용량을 맞춘 다 음 nylon 필터(Nylon membrane의 Millex filter unit, 공극 $0.2 \mu \mathrm{m}$, Millipore사)를 이용하여 여과하여 기기 분석용 시료로 하였다.

\subsection{2. 기기 분석}

$\mathrm{PFOA}$ 와 $\mathrm{PFOS}$ 의 정성 및 정량을 위해 $\mathrm{HPLC}$ 에 질 량분석기를 연결한 형태의 HPLC/MS/MS를 사용하였 다. HPLC는 Waters사의 Alliance 2695를 사용하였고, 질량분석기는 Micromass사의 Quattro micro API를 사 용하였다. 이온화장치는 음이온 전자분무식 이온화장 치를 적용하였고, 분석장치는 삼중(단계) 사중극자 질 량분석기(triple-quadrupole)를 이용하였다. 시료도입(도 입부)의 capillary voltage는 $3.5 \mathrm{kV}$ 로 고정하여 사용하 
였다. 시료가 도입되는 주입구의 온도는 $120^{\circ} \mathrm{C}$, 용매 제거를 위한 desolvation temp는 $420^{\circ} \mathrm{C}$, 용매제거와 분 석기로 유입되는 부근의 질소가스는 각각 desolvation gas flow를 $850 \mathrm{~L} / \mathrm{hr}$, cone gas flow를 $30 \mathrm{~L} / \mathrm{hr}$ 로 하여 분 석하였다. 시료 주입량은 $10 \mu \mathrm{L}$ 였으며, 이동상의 유량 은 분당 $300 \mu \mathrm{L}$ 로 하여 컬럼은 guard column(Zorbax Eclipse $\mathrm{XDB}_{-} \mathrm{C}_{8} 2.1 \times 12.5 \mathrm{~mm} 5 \mu \mathrm{m}$ )과 analysis column

PFOA

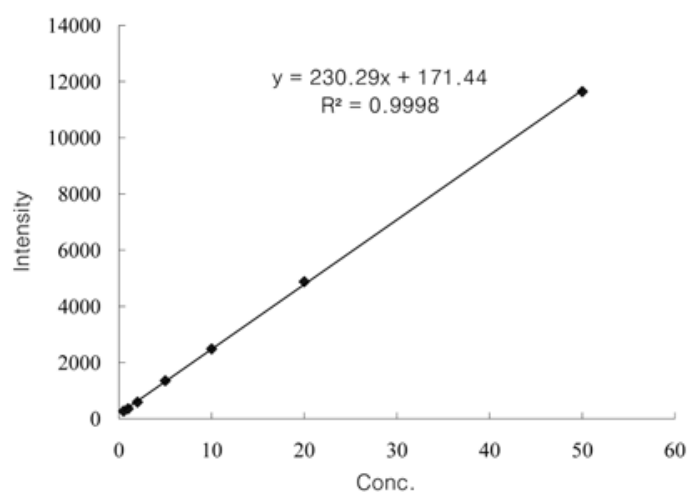

(Thermo Betasil ${ }^{\circledR} \mathrm{C}_{18} 2.1 \times 100 \mathrm{~mm} 5 \mu \mathrm{m}$ )을 직렬로 연결 하여 사용하였으며, 컬럼오븐의 온도는 $35^{\circ} \mathrm{C}$ 로 고정하 였다. 이동상은 $2 \mathrm{mM}$ 의 ammonium acetate와 메탄올로 하였으며, 이동상 비율변화는 시작 시에 $2 \mathrm{mM}$ ammonium acetate의 비가 $90 \%, 2$ 분 후에 $50 \%, 5$ 분 후에 $10 \%, 7$ 분 후에 $0 \%$, 다시 15 분 후에 $90 \%$ 에서 최 종 20 분까지 유지시켰다.

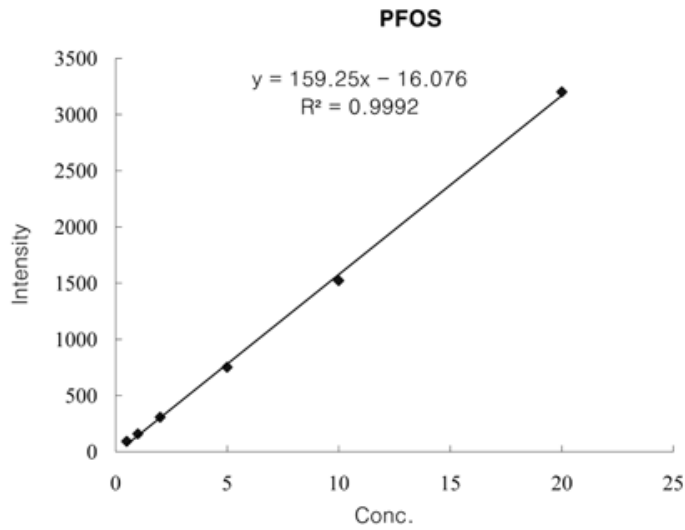

Fig. 2. Calibration curves of PFOA and PFOS (7 points; 0.5, 1, 2, 5, 10, 20, $50 \mu \mathrm{g} / \mathrm{L}$ ).

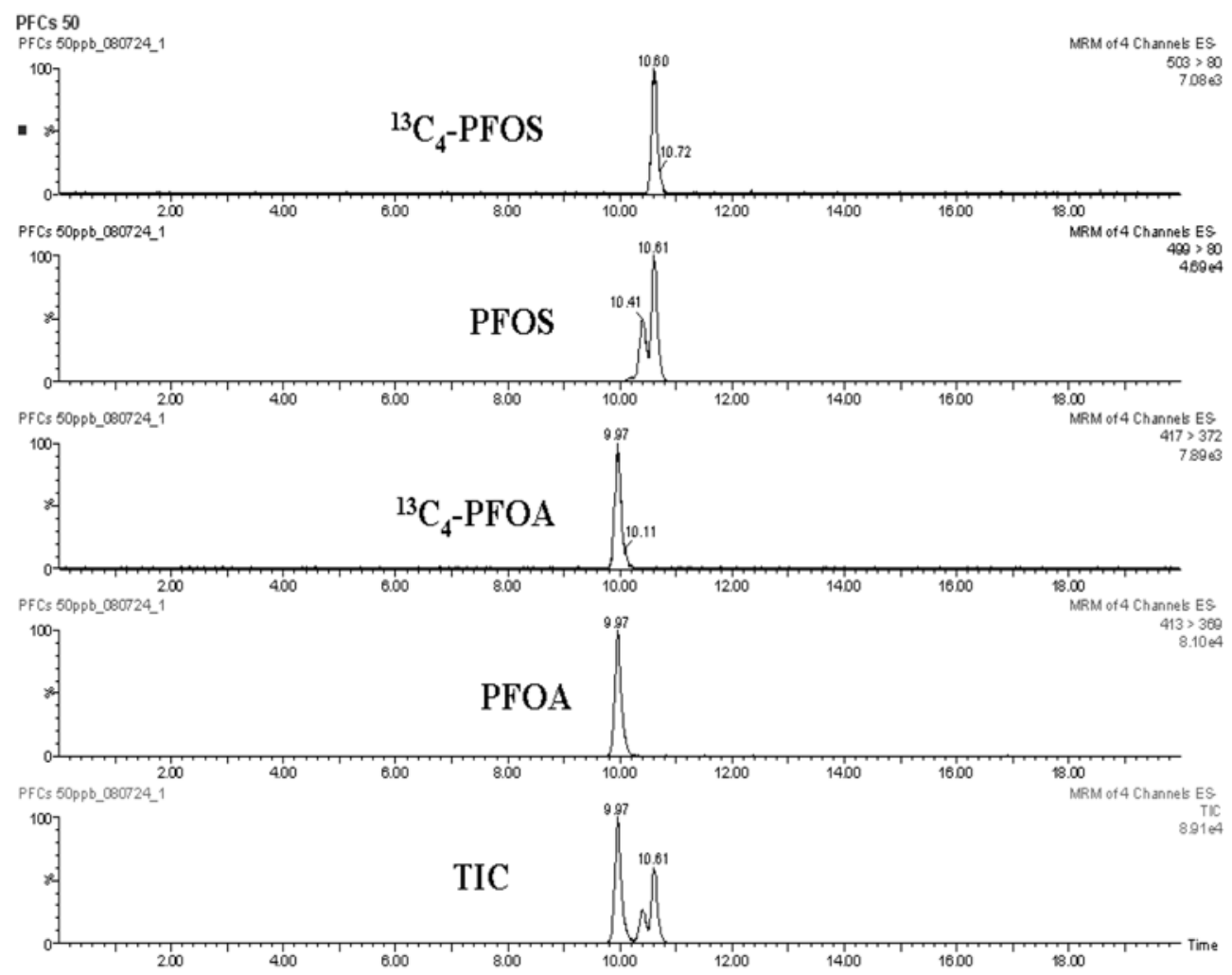

Fig. 3. Chromatogram of ${ }^{12} \mathrm{C}$ - and ${ }^{13} \mathrm{C}-\mathrm{PFOA} / \mathrm{PFOS}$ in standard solution (50 ppb). 
Table 2. Analytical conditions of LC/MS/MS in this study

\begin{tabular}{ll}
\hline \hline & \multicolumn{1}{c}{ HPLC } \\
\hline Instrument & Waters Allance 2695 \\
Column & Zorbax Eclipse XDB C8 $(2.1 \times 12.5 \mathrm{~mm}, 5 \mu \mathrm{m})$ \\
$\quad$ Guard column & Thermo Betasyl-C $18.1 \times 100 \mathrm{~mm}, 5 \mu \mathrm{m})$ \\
$\quad$ Analysis column & $\mathrm{A}(\mathrm{MeOH}), \mathrm{B}(2 \mathrm{mM}$ Ammonium acetate/water $)$ \\
Mobile phase & Time $(\mathrm{min}) 0-0.1-7-10-12-20$ \\
& $\mathrm{~A}(\%) \quad 10-30-75-100-100-10$ \\
& $300 \mu \mathrm{L} / \mathrm{min}$ \\
Mobile phase flow rate & $35{ }^{\circ} \mathrm{C}$ \\
Oven temp. & $10 \mu \mathrm{L}$ \\
Injection volume & \\
MS/MS & Quattro micro API \\
Instrument & $\mathrm{ESI}$ \\
Ionization & Negative mode \\
Polarity & $3.5 \mathrm{kV}$ \\
Capillary voltage & $120{ }^{\circ} \mathrm{C}$ \\
Source temp. & $420{ }^{\circ} \mathrm{C}$ \\
Desolvation temp. & $850 \mathrm{~L} / \mathrm{hr}$ \\
Desolvation gas flow & $30 \mathrm{~L} / \mathrm{hr}$ \\
Cone gas flow & ${ }^{12} \mathrm{C}-\mathrm{PFOA}(413-369),{ }^{13} \mathrm{C}-\mathrm{PFOA}(417-372)$ \\
MRM & ${ }^{12} \mathrm{C}-\mathrm{PFOS}(499-80),{ }^{13} \mathrm{C}-\mathrm{PFOS}(503-80)$ \\
& $\mathrm{PFOA}(15 \mathrm{~V}), \mathrm{PFOS}(55 \mathrm{~V})$ \\
Parameters & $\mathrm{PFOA}(10 \mathrm{eV}), \mathrm{PFOS}(55 \mathrm{eV})$ \\
Cone voltage &
\end{tabular}

분석시료의 정성과 정량분석은 이온의 질량을 측정 하여 검출하는 질량측정법을 사용하였으며, Micromass 사의 Quattro micro API를 사용하였다. 분석한 물질의 성분 확인은 표준물질과 시료의 머무름 시간을 비교 하였다. 분석대상물질의 검출방법은 특정 질량의 이온 만을 선택하여 검출하는 방법인 multiple reaction monitoring (MRM) mode를 이용하였으며, 정량용과 확인용 이온 각각의 precursor ion과 product ion을 확 인하였다. $\mathrm{PFOS}$ 는 $499>80, \mathrm{PFOA}$ 는 $413>369,{ }^{13} \mathrm{C}_{4}-$ $\mathrm{PFOS}$ 는 $503>80,{ }^{13} \mathrm{C}_{4}-\mathrm{PFOA}$ 는 $417>372$ 으로 생성된 이온들의 질량을 측정하여 정성분석을 실시하였으며, 분석대상물질의 정량이온 및 확인이온 피크가 예상 머무름 시간과 \pm 0.5 초 이내에 출현하고 $\mathrm{MRM}$ 에 의한 피크가 검출되면 물질이 존재하고 있다고 보았다. $\mathrm{PFOS}$ 와 PFOA 물질의 정량은 표준물질의 농도와 피 크의 면적을 이용하여 검량선을 작성하고 측정용 시 료의 분석대상물질과의 피크 면적을 이용하여 정량하 였다.

$\mathrm{PFOS}$ 와 $\mathrm{PFOA}$ 의 검 량선은 $0.5,1,2,5,10,20,50$ $\mu \mathrm{g} / \mathrm{L}$ 의 농도로 제조된 표준용액을 LC-MS/MS를 이용 하여 분석하고, 각 성분의 농도별 피크 면적을 이용하
여 1차식의 검량선을 작성하였다(Fig. 2). Fig. 3 및 Table 2에 PFOA 및 PFOS 표준물질의 크로마토그램 및 기기분석 조건을 나타내었다.

\section{4. 정도관리}

과불화화합물 분석시에는 기기의 공시료 값에 대한 주의가 필요하며, 충분히 공시료 값이 낮아짐을 확인 한 후에 분석을 시작하는 것이 좋다. 테플론 라인을 서스라인으로 교체하는 것이 한 방법이 될 수 있으며, 최근에는 서스라인으로 만들어진 기기가 시판되고 있 다. 본 연구에서는 현실적인 부분을 고려, 공시료 값 을 낮추기 위해 시료를 분석하기 전에 메탄올 용매를 20 개 이상 공시료로 주입하여 공시료 값을 낮춘 후 에 실제 시료를 분석하고, 시료의 타입이 바뀌는 경우 는 중간에 메탄올 공시료를 분석하여 공시료 값을 확 인하였다. 물론 시료 분석 후에도 메탄올 공시료를 20 개 이상 시료로 주입하였다. 또한 시료 중간에 QC 확 인용 표준물질을 추가하여 기기의 감도를 체크하였다. $\mathrm{LC} / \mathrm{MS} / \mathrm{MS}$ 기기분석 시 일정량의 시료를 찍은 후 멈 추었다가(기기의 전원은 on 상태) 다시 시료를 추가로 분석하는 경우에도 처음과 같이 PFOA/PFOS의 공시 
료 값이 높게 나타나기 때문에 가능하면 연속해서 시 료를 분석하는 것이 바람직할 것으로 판단된다.

대기 시료량을 $500 \mathrm{~m}^{3}$ 으로 한 경우, $\mathrm{PFOA} / \mathrm{PFOS}$ 의 검 량선을 이용하여 추정 된 LOD (Limit of detection) 및 $\mathrm{LOQ}$ (Limit of quantitation)는 $\mathrm{PFOA}$ 의 경우 $\mathrm{LOD}(\mathrm{S} / \mathrm{N}$ 비 $)$ 가 $0.02 \mathrm{pg} / \mathrm{m}^{3}, \mathrm{LOQ}$ 가 $0.06 \mathrm{pg} / \mathrm{m}^{3}$ 이었으 며, $\mathrm{PFOS}$ 의 경우 LOD가 $0.01 \mathrm{pg} / \mathrm{m}^{3}, \mathrm{LOQ}$ 가 0.03 $\mathrm{pg} / \mathrm{m}^{3}$ 이었다.

실제 분석된 시료 중 ${ }^{13} \mathrm{C}-\mathrm{PFOA}$ 및 ${ }^{13} \mathrm{C}-\mathrm{PFOS}$ 를 이 용하여 측정된 시료의 회수율은 각각 $30-53 \%$ (중간값 $49 \%$ ), $47 \sim 91 \%$ (중간값 $86 \%$ )로 가스상 ${ }^{13} \mathrm{C}-\mathrm{PFOA}$ 의 회 수율이 낮았으며, 이것은 PUF+XAD-2수지의 경우 최 종 농축액에서 현탁물질이 발생하여 nylon 필터로 2-3 회 추가 필터링을 수행했기 때문으로 생각된다. 또한 절대검량선법으로 정량을 수행한 것도 원인이 될 수 있다. 향후 이에 대한 보완으로 내부표준법을 이용하 는 것이 바람직할 것이다.

\section{3. 결과 및 고찰}

\section{1. 오염수준}

본 연구에서 분석한 대기 중 $\mathrm{PFOA}$ 및 $\mathrm{PFOS}$ 농도 를 Table 3에 정리하여 나타내었다.

Table 3에서 보는바와 같이 청주지역 대기 중 PFOA 및 $\mathrm{PFOS}$ 의 농도는 각각 불검출 $8.02 \mathrm{pg} / \mathrm{m}^{3}$ (평균 2.33 $\mathrm{pg} / \mathrm{m}^{3}$ ), $1.68 \sim 6.94 \mathrm{pg} / \mathrm{m}^{3}$ (평균 $3.12 \mathrm{pg} / \mathrm{m}^{3}$ ) 범위로 나 타났다. 채취지역별로 살펴보면 Fig. 4에 나타낸 바와 같이 공단지역의 경우 계절에 관계없이 $\mathrm{PFOA}>\mathrm{PFOS}$ 로 나타났으나 주거/상업 지역 및 농촌지역의 경우 $\mathrm{PFOA}<\mathrm{PFOS}$ 의 경향을 보였다.
물질별로 살펴보면, $\mathrm{PFOA}$ 의 경우 공단지역 > 주거 /상업지역>농촌 지역의 순으로 농도가 높게 검출되었 으며, PFOS는 채취지역에 관계없이 평균농도는 비슷 한 수준으로 나타났으며(공단지역: $2.85 \mathrm{pg} / \mathrm{m}^{3}$, 주거/ 상업지역: $3.98 \mathrm{pg} / \mathrm{m}^{3}$, 농촌지역 $\left.2.54 \mathrm{pg} / \mathrm{m}^{3}\right)$, 겨울철 주거/상업지역에서 가장 높은 농도 $\left(6.94 \mathrm{pg} / \mathrm{m}^{3}\right)$ 로 검 출되었다. 따라서 $\mathrm{PFOA}$ 는 시료 채취지역에 따라 다 른 농도 범위를 나타낸 반면, PFOS는 채취지역과 특 별한 상관성을 보이지 않았으며 이것은 이들 물질의 발생원 차이 때문인 것으로 생각된다. 또한 대기의 경 우 다른 지역으로부터의 이동에 의한 영향도 있을 수 있을 것으로 생각되나, 이에 대해서는 추가적인 연구 가 필요할 것으로 판단된다.

계절별로 살펴보면, $\mathrm{PFOA}$ 의 경우 겨울철>여름철> 봄철의 순으로, $\mathrm{PFOS}$ 는 겨울철>봄철>여름철의 순으 로 높은 농도를 나타내었다.

Table 4에 현재까지 보고된 국내외 대기 중 과불화 화합물(PFOA 및 $\mathrm{PFOS}$ )관련 자료를 정리하여 나타내 었다. Table 4에서 보는 바와 같이, 대기를 대상으로 한 연구는 현재까지 매우 적으며, 본 연구의 대상지역인 청주의 대기 중 PFOA 및 PFOS는 일본의 Morioka, Iwate, 미국의 Albany 및 독일의 대기와 유사한 수준으 로 나타났으며, 일본의 Kyoto, Oyamazaki 보다는 낮은 수준을 보였다.

본 연구에서 측정한 대기 중 가스상 및 입자상에 결합되어 있는 $\mathrm{PFOA}$ 및 $\mathrm{PFOS}$ 의 농도와 대기환경인 자(기온, TSP농도, 상대습도, 풍속) 간의 상관관계를 조사한 결과, 가스상 형태로 존재하는 $\mathrm{PFOA}$ 는 기온 $(\mathrm{r}=0.633), \mathrm{TSP}(\mathrm{r}=-0.821)$ 및 상대습도 $(\mathrm{r}=0.953)$ 와 높은 상관성을 보인 반면, 가스상 $\mathrm{PFOS}$ 는 PFOS 총농도

Table 3. Concentrations of PFOA and PFOS in ambient air, Cheongju city

\begin{tabular}{|c|c|c|c|c|c|c|c|c|}
\hline \multirow{2}{*}{$\begin{array}{c}\text { Sampling } \\
\text { Season }\end{array}$} & \multirow{2}{*}{$\begin{array}{l}\text { Sampling* } \\
\text { Region }\end{array}$} & \multirow{2}{*}{$\begin{array}{c}\text { Sample } \\
\text { ID }\end{array}$} & \multicolumn{2}{|c|}{$\begin{array}{l}\text { PFOA } \\
\left(\mathrm{pg} / \mathrm{m}^{3}\right)\end{array}$} & \multicolumn{2}{|c|}{$\begin{array}{l}\text { PFOS } \\
\left(\mathrm{pg} / \mathrm{m}^{3}\right)\end{array}$} & \multirow{2}{*}{$\begin{array}{c}\text { PFOA } \\
\text { (ng/g) }\end{array}$} & \multirow{2}{*}{$\begin{array}{c}\begin{array}{c}\text { PFOS } \\
(\mathrm{ng} / \mathrm{g})\end{array} \\
\text { Particle }\end{array}$} \\
\hline & & & Gas & Particle & Gas & Particle & & \\
\hline \multirow{3}{*}{ Winter } & I & W-I & n.d & 8.02 & 2.92 & 1.25 & 23.82 & 3.73 \\
\hline & $\mathrm{R} / \mathrm{C}$ & $\mathrm{W}-\mathrm{R} / \mathrm{C}$ & n.d & 1.17 & 2.72 & 4.22 & 5.24 & 18.94 \\
\hline & $\mathrm{R}$ & W-R & n.d & 0.19 & 1.78 & 1.40 & 0.84 & 6.29 \\
\hline \multirow{3}{*}{ Spring } & I & Sp-I & n.d & 3.04 & 0.11 & 1.57 & 15.65 & 8.07 \\
\hline & $\mathrm{R} / \mathrm{C}$ & $\mathrm{Sp}-\mathrm{R} / \mathrm{C}$ & n.d & n.d & 1.18 & 2.07 & n.d & 8.28 \\
\hline & $\mathrm{R}$ & Sp-R & n.d & n.d & 1.73 & 0.96 & n.d & 3.13 \\
\hline \multirow{3}{*}{ Summer } & I & Su-I & 2.17 & 3.63 & 2.59 & 2.64 & 43.50 & 31.70 \\
\hline & $\mathrm{R} / \mathrm{C}$ & $\mathrm{Su}-\mathrm{R} / \mathrm{C}$ & 1.77 & n.d & 0.98 & 0.79 & n.d & 9.46 \\
\hline & $\mathrm{R}$ & Su-R & 1.00 & n.d & 0.81 & 0.92 & n.d & 16.62 \\
\hline
\end{tabular}

$* \mathrm{I}, \mathrm{R} / \mathrm{C}$, and $\mathrm{R}$ means industrial region, residential/commercial region, and rural region, respectively. 


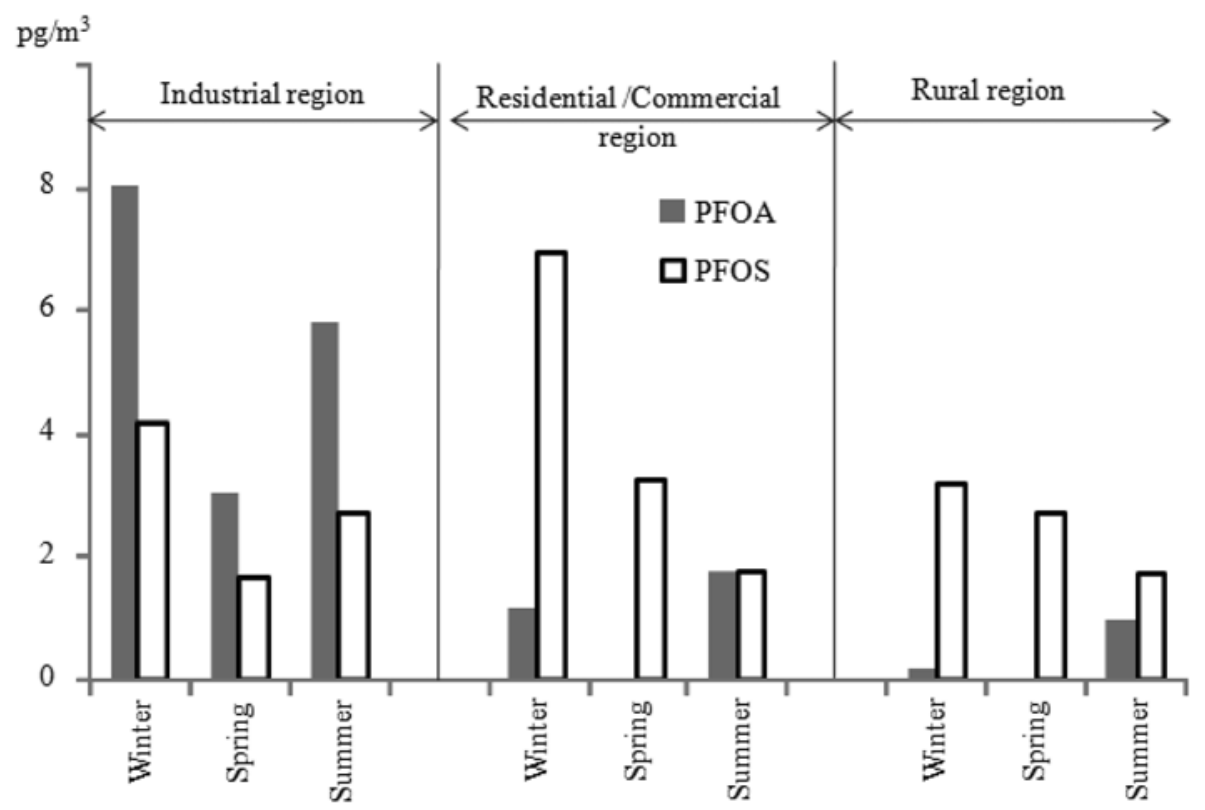

Fig. 4. Distribution of concentration of PFOA and PFOS in ambient air by sampling regions.

Table 4. Concentrations of PFOA and PFOS in ambient air in previous literatures

\begin{tabular}{|c|c|c|c|c|c|}
\hline Country & Sampling site & PFOA $\left(\mathrm{pg} / \mathrm{m}^{3}\right)$ & PFOS $\left(\mathrm{pg} / \mathrm{m}^{3}\right)$ & Remark & References no. \\
\hline \multirow{3}{*}{ Korea } & \multirow{3}{*}{ Cheongju ( $\mathrm{n}=9$ ) } & n.d-2.17 (0.55) & $0.11-2.92(1.65)$ & gas & \multirow{3}{*}{ this study } \\
\hline & & n.d-8.02 (1.78) & $0.79-4.22(1.76)$ & particle & \\
\hline & & n.d-8.02 (2.33) & $1.68-6.94(3.41)$ & total & \\
\hline \multirow{4}{*}{ Japan } & Oyamazaki $(n=12)$ & $72-919$ (262.7) & $2.51-9.80(5.2)$ & & \multirow{3}{*}{18} \\
\hline & Morioka $(\mathrm{n}=8)$ & $1.59-2.58(2.0)$ & $0.46-1.19(0.7)$ & & \\
\hline & Iwate $(n=8)$ & $3.2-5.2(3.9)$ & $0.6-2.4(1.2)$ & & \\
\hline & Kyoto $(\mathrm{n}=8)$ & $72-407$ (172) & $2.5-8.0(5.0)$ & & \multirow[t]{2}{*}{19} \\
\hline China & Shenyang $(n=8)$ & $2.3-15(5.5)$ & $0.2-1.6(0.6)$ & & \\
\hline \multirow{2}{*}{ USA } & Albany $(n=8)$ & $1.89-6.53(3.16)$ & $0.94-3.0(1.70)$ & gas & \multirow{2}{*}{15} \\
\hline & Albany $(n=8)$ & $0.76-4.19(2.03)$ & $0.35-1.16(0.64)$ & particle & \\
\hline \multirow{3}{*}{ Germany } & Bight $(n=7)$ & $1.9-6.1(2.8)$ & $0.1-2.3(1.1)$ & \multirow{3}{*}{ particle phase } & \multirow{3}{*}{20} \\
\hline & $\operatorname{Bar}(n=2)$ & $0.6,0.7$ & $1.6,9.1$ & & \\
\hline & GKSS $(n=2)$ & $0.6,1.0$ & $0.2,0.2$ & & \\
\hline
\end{tabular}

$(\mathrm{r}=0.845)$ 와만 상관성을 나타내었다.

입자상 $\mathrm{PFOA}$ 및 $\mathrm{PFOS}$ 는 각각 $\mathrm{PFOA}(\mathrm{r}=0.951)$ 및 $\operatorname{PFOS}(\mathrm{r}=0.883)$ 의 총 농도와 높은 상관성을 보여 대기 중 PFOA와 PFOS는 입자와 결합되어진 상태로 존재 하는 비율이 높음을 알 수 있다.

\section{2. 가스-입자 분배}

Table 3에서 보는 바와 같이 $\mathrm{PFOA}$ 의 경우 1 개 시 료에서만 가스상과 입자상 농도가 검출되었기 때문에
가스-입자 분배 등의 대기 중 거동과 관련된 해석을 할 수 없었다. 따라서 여기서는 가스상과 입자상 모두 에서 검출된 $\mathrm{PFOS}$ 를 대상으로 가스-입자 분배를 해 석하였다.

Table 5 및 Fig. 5에 대기 중 $\mathrm{PFOS}$ 의 기온과 $\mathrm{TSP}$ 농 도를 고려한 가스-입자분배계수 $(\log \mathrm{K}=(\mathrm{Cp} / \mathrm{TSP}) / \mathrm{Cg}$, $\left.\left[\mathrm{m}^{3} / \mu \mathrm{g}\right]\right)$ 와의 관계를 나타내었다. Fig. 5에서 보는 바 와 같이 기온이 상승할수록 분배계수 값이 커지는 경 향성을 보이고 있다. 이것은 PFOS가 온도의 변화에 
Table 5. Gas-particle partitioning coefficients ( $\log \mathrm{K})$ and fractions of particle for PFOS

\begin{tabular}{lrrrrrrrrr}
\hline \hline & W-I & W-R/C & W-R & Sp-I & Sp-R/C & Sp-R & Su-I & Su-R/C & Su-R \\
\hline 1000/T (K) & 3.74 & 3.70 & 3.73 & 3.44 & 3.43 & 3.45 & 3.37 & 3.36 & 3.37 \\
TSP $\left(u g / m^{3}\right)$ & 168.4 & 111.4 & 111.3 & 97.2 & 125.0 & 152.8 & 41.7 & 41.7 & 27.8 \\
Fraction of particle (\%) & 30 & 61 & 44 & 93 & 64 & 36 & 51 & 45 & 53 \\
$\log$ K & -2.59 & -1.86 & -2.15 & -0.84 & -1.85 & -2.44 & -1.61 & -1.71 & -1.39 \\
\hline
\end{tabular}

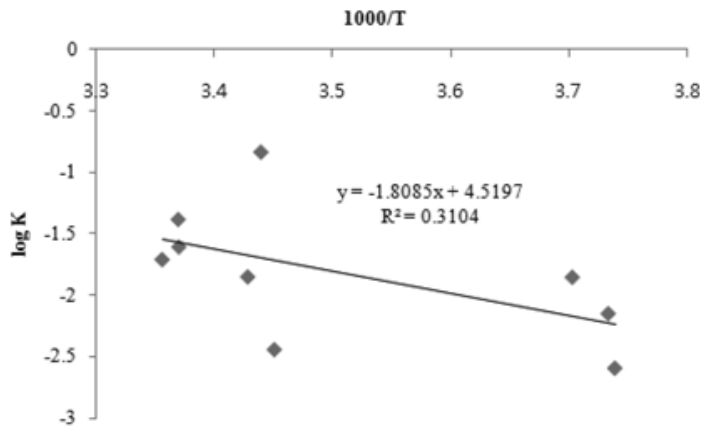

Fig. 5. $\log \mathrm{K}$ versus temperature for PFOS.

따라 입자에 결합하는 비율이 서로 달라지는 현상으 로 겨울철에는 높은 입자결합비율을 보이고 반대로 여름철에는 가스형태로 존재하는 비율이 커지는 것을 의미한다. 그러나 결정계수값 $\left(\mathrm{R}^{2}\right)$ 이 0.3 으로 낮았으며 통계적 유의성(신뢰수준 95\%)도 없었다. 이러한 이유 로는 PFOS가 다른 POPs 물질과 달리 휘발성이 낮아 서 Kow나 Koa가 상대적으로 작기 때문으로 판단된 다. Arp H.P.H 등(2006)이 정리하여 보고한 분배계수 및 관련된 인자들은 예측 모델에 따라 다양한 편차를 보이고 있으며, $\mathrm{PFOA}$ 및 $\mathrm{PFOS}$ 에 대한 증기압 및 분 배계수의 온도 등에 대한 관계값들이 아직 보고되지 않아 본 연구에서 가스-입자 분배평형 및 거동해석에 관련된 해석에는 한계가 있었다.

\section{4. 결 론}

본 연구에서는 청주시의 공단, 주거/상업 및 농촌지 역에서 겨울철, 봄철 및 여름철에 각각 대기 중 PFOA 및 $\mathrm{PFOS}$ 를 가스상과 입자상으로 나누어 분석하였다. 대기 중 PFOA 및 PFOS의 오염수준은 기 보고된 외국 의 중소도시와 비슷한 수준을 나타내었으나 대도시에 비해서는 낮은 수준으로 나타났다. PFOA의 경우 주로 입자상에서 검출되었으며, PFOS는 가스상, 입자상 모 두 검출되었다. 시료채취시의 기온과 가스-입자분배계 수와의 상관성은 나타나지 않았으며 이것은 이들 물질
의 휘발성이 매우 낮기 때문으로 판단된다.

\section{감사의 글}

본 연구는 2007년도 정부재원(교육인적자원부 학술 연구조성사업비)으로 한국학술진흥재단의 지원을 받 아 연구되었음(KRF-2007-313-D00418).

\section{참고문헌}

1. 3M, "Environmental and health assessment of perfluorooctane sulfonic acid and its salt", prepared by $3 \mathrm{M}$ company, 2003.

2. C. Caliebe, W. Gerwinski, H. Hühnerfuss and N. Theobald, Organohalogen Compounds, 66, 4074-4078(2004).

3. K. Kannan, J. Koistinen, K. Beckmen, T. Evans, J. F. Gorzelany, K. J. Hansen, P. D. Jones, E. Helle, M. Nyman, and J. P. Giesy, Environ. Sci. Technol., 35(8), 1593-1598(2001).

4. G. M. Rusch, W. E. Rinehart, and C. A. Bozak, Acute inhalation toxicity study of $\mathrm{T}-2306 \mathrm{CoC}$ in the rat. project no. 78-7185, Bio/dynainics Inc., 1979.

5. F. D. Gilliland, and J. S. Mandel, American jeournal of industrial medicine, 29(5), 560-568(1996).

6. W. P. Dean, D. C. Jessup, G. Thompson, G. Romig, D. Powell, Fluorad fluorochemical surfactant FC-95 acute oral toxicity (LD50) study in rats. Study no. 137-083. International Research and Development Cooperation, 1978.

7. $3 \mathrm{M}$, "Screening studies in the aqueous photolytic degradation of perfluotooctanoic acid", USEPA administrative record AR226-1030 photolysis E00-2192, 2001.

8. J. P. Giesy and K. Kannan, Environ. Sci. Technol., 35, 1339-1342(2001).

9. N. Yamashita, K. Kannan, S. Taniyasu, Y. Horii, G. Petrick and T. Gamo, Mar. Pollut. Bull., 51, 658-668(2005).

10. A. Janke, U. Berger, R. Ebinghaus, and C. Temme, Envi- 
ron. Sci. Technol., 41(9), 3055-3061(2007).

11. C. J. Young, VI. Furdui, J. Franklin, R. Koerner, D. C. G. Muir, and S. A. Mabury, Environ. Sci. Technol., 41(10), 3455-3461(2007).

12. 신미연, 손현석, 조경덕, 대한환경공학회 추계학술연 구발표회 논문집, 대한환경공학회, 1187-1194(2007).

13. 정재연, 윤해승, 류희영, 원종욱, 팽기정, 김연제, 분 석과학, 21(3), 183-190(2008).

14. 岩手環境保健究センタ, 化學物質と環境 平成 15 年 化 學物質分析法開發調査報告書, 2004 .

15. S. K. Kim and K. Kannan, Environ. Sci. Technol., 41(24), 8328-8334(2007).
16. M. Shoeib, T. Harner, B. H. Wilford, K. C. Jones, and J. Zhu, Environ. Sci. Technol., 39(17), 6599-6606(2005).

17. C. P. Higgins, J. A. Field, C. S. Criddle, and R. G. Luthy, Environ. Sci. Technol., 39(11), 3946-3956(2005).

18. K. Harada, S. Nakanishi, N. Saito, T. Tsutsui, and A. Koizumi, Bull. Environ. Contam. Toxicol., 74, 64-69(2005).

19. K. Sasaki, T. Yoshida, K. Ozawa, N. Saito, Y. Jin, A. Koizumi, China-Japan joint symposium on environmental chemistry, Beijing, 2004.

20. A. Dreyer and R. Ebinghaus, Atmospheric Environment, 43, 1527-1535(2009). 